\title{
Cloning, expression and characterization of alcohol dehydrogenases in the silkworm Bombyx mori
}

\author{
Nan Wang, Haifeng Shi, Qin Yao, Yang Zhou, Lequn Kang, Huiqin Chen and Keping Chen \\ Institute of Life Sciences, Jiangsu University, Zhenjiang, Jiangsu Province, P.R. China.
}

\begin{abstract}
Alcohol dehydrogenases (ADH) are a class of enzymes that catalyze the reversible oxidation of alcohols to corresponding aldehydes or ketones, by using either nicotinamide adenine dinucleotide (NAD) or nicotinamide adenine dinucleotide phosphate (NADP), as coenzymes. In this study, a short-chain ADH gene was identified in Bombyx mori by 5'-RACE PCR. This is the first time the coding region of BmADH has been cloned, expressed, purified and then characterized. The CDNA fragment encoding the BmADH protein was amplified from a pool of silkworm cDNAs by $\mathrm{PCR}$, and then cloned into E. coli expression vector pET-30a(+). The recombinant His-tagged BmADH protein was expressed in E. coli BL21 (DE3), and then purified by metal chelating affinity chromatography. The soluble recombinant $\mathrm{BmADH}$, produced at low-growth temperature, was instrumental in catalyzing the ethanol-dependent reduction of $\mathrm{NAD}^{+}$, thereby indicating ethanol as one of the substrates of $\mathrm{BmADH}$.
\end{abstract}

Key words: 5'-RACE PCRADH, enzymatic activity, recombinant protein.

Received: September 28, 2010; Accepted: February 17, 2011.

Alcohol dehydrogenases (ADH; EC 1.1.1.1) belong to the oxidoreductase family, a class of enzymes, instrumental in catalyzing the reversible oxidation of alcohols to corresponding aldehydes or ketones, by using either NAD or NADP as coenzymes. ADHs are widely distributed in nature and have been found in species throughout the three domains of life, Archaea, Bacteria and Eukarya (Branden et al., 1975; Reid and Fewson, 1994; Rella et al., 1987). ADHs play important roles in a wide range of physiological processes. Based on their catalytic activities, they presumedly participate in the metabolism of steroids, retinoids, lipid peroxidation products, $\omega$-hydroxy fatty acids, xenobiotic alcohols and aldehydes (Doga, 2010). Based on molecular size and cofactor requirements, ADHs are generally classified into three subfamilies: Type I, the medium-chain zinc-dependent, such as horse liver ADHs and ADHs (isozymes I-III) in Saccharomyces cerevisiae (Adolph et al., 2000), contain approximately 370 amino acids per subunit, and form dimers (in higher eukaryotes) or tetramers (in bacteria); Type II, the short-chain zinc-independent ADHs , such as in Drosophila melanogaster (Benach et al., 2005), contain approximately 250 amino acids per subunit and, rarely, metals; and Type III, the long-chain iron-activated ADHs, such as ADH IV from $S$. cerevisiae (Williamson and Paquin, 1987), contain 385 to 900 amino acid residues per subunit.

Send correspondence to Keping Chen. Institute of Life Sciences, Jiangsu University, 301\# Xuefu Road, Zhenjiang, Jiangsu Province, 212013 P.R. China. E-mail: kpchen@ujs.edu.cn.
In insects, ADHs primarily break down dietary alcohols produced by microbial fermentation (Atrian et al., 1998). A number of short-chain ADH genes have been cloned and characterized from a variety of fruit-fly species, such as Drosophila melanogaster (Benach et al., 1999), Drosophila lebanonensis (Benach et al., 1999), Ceratitis capitata (Mediterranean fruit flies) (Gasperi et al., 1994) and Bactrocera (Dacus) oleae (olive fly) (Mazi et al., 1998). Whereas short-chain ADHs from Drosophila and certain closely related insects use small alcohols as substrates, all the other known members of this group are mostly steroid and prostaglandin dehydrogenases of both prokaryotic and mammalian origin (Benach et al., 2005). Although much exhaustive biochemical work has been undertaken with Drosophila ADHs, few short-chain ADHs from other insects has been functionally characterized.

In this study, the open reading frame (ORF) of putative Bombyx mori alcohol dehydrogenases, denominated BmADHs, was cloned, and the recombinant enzymes expressed in Escherichia coli. The ethanol dehydrogenase activity of the resultant recombinant proteins was assayed.

An EST, highly similar to Bombyx mori ADH cDNA, was identified in the GenBank database (Accession No. rswdd0_001984EST). In order to obtain the full-length cDNA sequence, 5'-RACE was carried out with the SMART RACE cDNA kit (Clontech, CA, USA) by using $1 \mu \mathrm{g}$ of poly $(\mathrm{A})^{+}$mRNA from the posterior silk gland of $B$. mori and a gene-specific reverse (5'-TGT AAA GGA TTG 
CAG TGT CAG TGG-3') and forward primer (5'-AAG CAG TGG TAT CAA CGC AGA GT-3') both obtained from Clontech. Specific bands were retrieved, subcloned into pMD-18T vector and identified as a $773 \mathrm{bp}$ cDNA fragment by DNA sequencing. A $1104 \mathrm{bp}$ cDNA sequence containing a complete 822 bp ORF (GenBank accession number DQ512730) encoding a 274 amino acid protein with conserved short-chain ADH domain was obtained from alignment of the obtained fragment and EST.

By comparing the new identified sequence with contigs of B. mori genome in GenBank using BLAST and SIM4, five exons and four introns were revealed. The orthologous sequences retrieved from the NCBI database indicated identity of the deduced amino acid sequence of BmADH (GenBank accession no.NP_001037610.1) to be $32 \%, 31 \%$ and $30 \%$ with the Homo sapiens 15 -hydroxyprostaglandin dehydrogenase (Hs15HPGDH), D. lebanonensis alcohol dehydrogenase (DlADH) and D. melanogaster alcohol dehydrogenase (DmADH), respectively (Figure. 1). On numbering DmADH, the triad of active site residues, Ser139, Tyr152 and Lys156, intimately involved in the enzyme reaction, were found to be conserved in the $\mathrm{BmADH}$ protein (Figure. 1).

BmADH specific primers, the forward 5'-GGGGA TCCATGGCACCGGATTTCGTG-3' with a BamHI site, and reverse 5'-CCCTCGAGCTATGTCTTGGAGAGTA TTTGGAAG-3' with an XhoI site, were designed to amplify the ORF of a putative BmADH gene from a pool of

\section{DmADH --- MSFTLTNKNVIFVAGLGGIGLDTSKELLKRDLKNLVILDRIENPAAIAELKAI 53 \\ DIADH \\ BmADH \\ Hs $15 \mathrm{HDPGDH}$ \\ DmADH \\ DIADH \\ BmADH \\ Hs 15HDPGDH \\ DmADH \\ DIADH \\ BmADH \\ Hs 15HDPGDH \\ DmADH \\ DIADH \\ BmADH \\ Hs 15HDPGDH \\ DmADH \\ DIADH \\ BmADH \\ Hs15HDPGDH \\ --_--MDLTNKNVIFVAALGGIGLDTSRELVKRNLKNFVILDRVENPTALAELKAI 51 MAPDFVKRFVDVDDKVFLVTGGAAGVGAGLVKALLFENARHVAFLDVADREGAALEAQLI 60 -MHVNGKVALVTGAAQGIGRAFAEALLLKGAK-VALVDWNLEAGVQCKAALD 50 \\ N--PKVTVTFYPYDVTVPIAETTKLLKTIFAQLKTVDVLINGAGIL--DDHQIERTIAVN 109 N--PKVNITFHTYDVTVPVAESKKLLKKIFDQLKTVDILINGAGIL--DDHQIERTIAIN 107 IKFGALRVKFIKCDVGD-ERQLASAYKQVLDKYKRLDGVINSAAVLSVDDNSFNRMIDIN 119 EQFEPQKTLFIQCDVAD-QQQLRDTFRKWDHFGRLDILVNNAGVN--NEKNWEKTLQIN 107 * ** : : : : : : : :*::*.* : ::: :: : :* \\ YTGL VNTTTAILDFWDKRKGGPGGIICNIGSVTGFNAIYQVPVYSGTKAAVVNFTSSLAK 169 FTGL VNTTTAILDFWDKRKGGPGGIIANICSVTGFNAIHQVPVYSASKAAVVSFTNSLAK 167 FTGTVNSTLKALDIMGADKGGSGGVIVNISSLLALNLTSHLPVYAATKAAVLQFSIRVGT 179 LVSVISGTYLGLDYMSKQNGGEGGIIINMSSLAGLMPVAQQPVYCASKHGIVGFTRSAAL 167

$$
\therefore * \quad * * . \quad: * * * * * *: \underline{*} . .: \quad: * * \ldots \ldots . . . .: * \text { : }
$$ \\ LAPITG--VTAYTVNPGITRTTLVHKFN--—-SWLDVEPQVAEKLLAHPTQPSLACAE 221 LAPITG--VTAYSINPGITRTPLVHTFN---—SWLDVEPRVAELLLSHPTQTSEQCGQ 219 QEQFTRTKVRVLSVCLGPTDTAILYKNNL---—TKFDTEYAPCLSSRAPVRQRVESAVK 234 AANLMNSGVRLNAICPGFVNTAILESIEKEENMGQYIEYKDHIKDMIKYYGILDPPLIAN 227 * :: * * * : : . \\ $::$ : \\ NFVKAIELNQNGAIWKLDLGTLEAIQWTKHWDSGI----- 256 NFVKAIEANKNGAIWKLDLGTLEAIEWTKHWDSHI----- 254 GILEVINKASTGDTWIVES-DKPAYDFTQNISEAFQILSKT 274 GLITLIEDDALNG-AIMKITTSKGIHFQDYDTTPFQAKTQ- 266 \\ $\therefore *$ : . . . . . .}

Figure 1 - Amino acid sequence alignment of deduced BmADH, Homo sapiens 15-hydroxyprostaglandin dehydrogenase (Hs15HPGDH), D. lebanonensis alcohol dehydrogenase (D1ADH), and D. melanogaster alcohol dehydrogenase (DmADH). Accession numbers are NP_001037610.1, P15428, P10807 and P00334, respectively. * indicates identical residues; ${ }_{-}^{*}$ indicates enzyme active-center residues; : indicates conserved residues; . indicates semi-conserved residues. silkworm cDNAs. The tissue expression profile of BmADH was investigated, through RT-PCR analysis of total RNAs isolated from silk glands, malpighian tubules, spermaries, eggs, fat body, ovaries, ganglia, hemocytes, epidermis, hindgut, and midgut of fifth instar larvae. BmADH transcripts were detected in all the examined tissues. The expression levels in hemocytes and the hindgut were higher, when compared to those in other tissues (Figure. 2).

The PCR product, first ligated into the pMD18-T vector using T4 DNA ligase, was then transformed into E. coli TG1. A fragment, between BamHI and XholI and containing the BmADH gene, was excised from the recombinant plasmid. The purified fragment was subcloned into the pET-30a $(+)$ expression vector and transformed into $E$. coli BL21 (DE3). DNA sequencing confirmed correct BmADH ORF fusion to the N-terminal 6xHis tag.

To express recombinant protein, a freshly transformed colony was cultured in LB medium with kanamycin $(50 \mu \mathrm{g} / \mathrm{mL})$ at $37^{\circ} \mathrm{C}$, with vigorous shaking. So as to obtain a soluble protein, on $\mathrm{OD}_{600}$ reaching $0.6, \mathrm{BmADH}$ expression was induced with IPTG (final concentration $0.4 \mathrm{mM}$ ), and further cultured at $16^{\circ} \mathrm{C}$ for $20 \mathrm{~h}$. SDS-PAGE analysis of the E.coli lysate revealed that recombinant protein was expressed and the molecular mass was about $31 \mathrm{kDa}$. The expression of $6 x$ His-tagged BmADH was confirmed by mouse anti-6xHis monoclonal antibody (1:500 dilution) for $2 \mathrm{~h}$, followed with peroxidase-conjugated goat anti-mouse $\operatorname{IgG}(1: 1000$ dilution) for another $2 \mathrm{~h}$ to display color, as described previously (Huo et al., 2010).

For purification of recombinant $\mathrm{BmADH}$ protein, $E$. coli BL21 cells were harvested by centrifugation $(4500 \mathrm{x} \mathrm{g}$, $4{ }^{\circ} \mathrm{C}, 15 \mathrm{~min}$ ). The cell pellet was resuspended in buffer $\mathrm{A}$ (50 mM sodium phosphate, $300 \mathrm{mM} \mathrm{NaCl}, 1 \mathrm{mM}$ EDTA, $0.5 \mathrm{mM}$ PMSF, $\mathrm{pH} 8.0$ ), the resultant cell-suspension then being lysed by sonication. The lysate was clarified by centrifugation $\left(16,000 \mathrm{x} \mathrm{g}, 4{ }^{\circ} \mathrm{C}, 25 \mathrm{~min}\right)$. The supernatant was then loaded onto a Ni-NTA affinity column (Qiagen). Purification conditions were standardized by optimizing the $\mathrm{pH}$, the concentrations of salt and imidazole. After washing the captured column with $50 \mathrm{mM}$ imidazole, the fusion protein was eluted with $250 \mathrm{mM}$ imidazole. The eluted protein was dialyzed against buffer B $(50 \mathrm{mM}$ sodium phosphate, $150 \mathrm{mM} \mathrm{NaCl}, \mathrm{pH} 7.5)$ at $4{ }^{\circ} \mathrm{C}$. The concentration of protein was determined by the Bradford

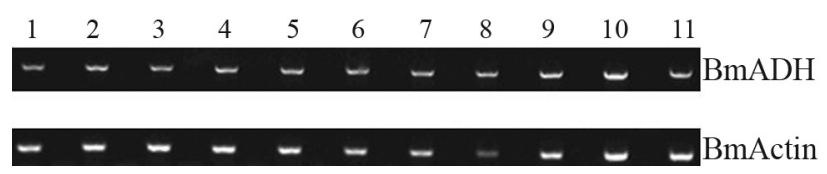

Figure 2 - Expression profile of the BmADH gene in various tissues of $B$. mori. Top: lane1, silk gland; lane 2, malpighian tubule; lane 3, spermarium; lane 4, egg; lane 5, fat body; lane 6, ovary; lane 7, ganglion; lane 8, hemocytes; lane 9, epidermis; lane 10, hindgut; lane 11, midgut. An actin gene of B. mori was used as internal control in the corresponding tissues. 
method, the estimated purity being over $80 \%$, according to SDS-PAGE analysis (Figure 3A).

The specific bands corresponding to BmADH proteins were analyzed by an ultraflex MALDI-TOF-TOF instrument (Bruker, Germany), whereupon twelve peptide fragments were identified. Peptide mass fingerprinting (PMF) was performed by comparing the masses of identified peptides to those of hypothetical tryptic peptides for proteins in a non-redundant NCBI database, using the MASCOT search engine. BmADH was clearly identified, with a MOWSE score of 86 . The sequences of the 12 identified peptide fragments accounted for $45 \%$ of amino acid sequences in $\mathrm{BmADH}$.

The catalyzing activity of recombinant BmADH was assayed spectrophotometrically by measuring the increase in absorbance at $340 \mathrm{~nm}$, following the reduction of $\mathrm{NAD}^{+}$ to NADH in a solution containing substrate ethanol, as described by Oudman et al. (1991). Briefly, $3 \mathrm{~mL}$ of reaction buffer $(50 \mathrm{mM} \mathrm{NaOH} /$ Glycine buffer, $\mathrm{pH} 9.0,0.67 \mathrm{M}$ ethanol and $8 \mathrm{mM} \mathrm{NAD}^{+}$) were incubated at $25^{\circ} \mathrm{C}$, and the reaction was initiated by adding $0.1 \mathrm{~mL}$ of purified proteins. The rate of increase at $\mathrm{A}_{340}$ in the first 6 min was in linear range and was recorded. The rate of increase for the reaction buffer, but without a protein sample, was used as the blank. An extinction coefficient of $6.22 \mathrm{mM}^{-1} \mathrm{~cm}^{-1}$ for NADH was used for calculating enzyme activity (Zhang et al., 2006). One unit of dehydrogenase activity is defined as $1 \mu \mathrm{mol} \mathrm{NAD}{ }^{+}$reduced per min. The enzyme specific-activity-calculation formula is as follows: $\left(\mathrm{A}_{340} \mathrm{x} \mathrm{V}\right) /(6.22 \mathrm{xb}$ $\mathrm{x} \mathrm{W}$ )where $\mathrm{A}_{340}$ is the change in absorbance at $340 \mathrm{~nm}$ per $\mathrm{min}, \mathrm{V}$ the final reaction volume, $\mathrm{b}$ the light path, and $\mathrm{W}$ the

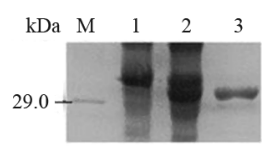

(A)

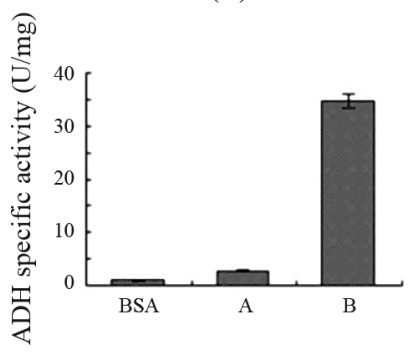

(B)
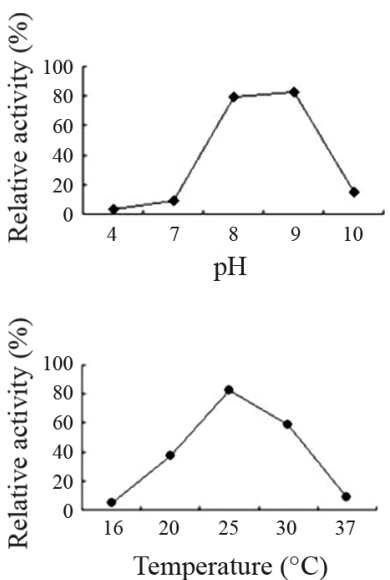

(C)

Figure 3 - Electrophoretic and enzymatic characterization and stability of BmADH. (A) SDS-PAGE stained with Commassie blue. M marker: lane 1 - lysate of host cells transformed with empty vector; lane 2 - lysate of host cells with $\mathrm{BmADH}$ expressionlane 3 - recombinant $\mathrm{BmADH}$ purified by Ni-NTA resin column. (B) Alcohol dehydrogenase specific activity, with BSA (bovine serum albumin) as negative control. A: cell lyaste of BL21 (DE3) with BmADH expression. B: purified BmADH protein. Data represent mean \pm S.D. * indicates $p<0.01$ compared to BSA. (C) Stability of alcohol dehydrogenase activity at different pHs and temperatures. Each point represents the average of duplicate determination.

amount of protein in the reaction system. A non-related protein bovine serum albumin (BSA) was used as negative control. Purification of recombinant BmADH by the NiNTA column increased specific dehydrogenase activity around 6-fold to $80 \mathrm{unit} / \mathrm{mg}$ (Figure 3B). This specific recombinant BmADH activity, measured by ethanol-dependent reduction of the $\mathrm{NAD}^{+}$reaction, was comparable to ADH activity assayed in whole-larval homogenates of $D$. lebanonensis (0.5-1 unit/mg) (Geer et al., 1988).

Enzyme pH stability was determined by measuring enzymatic activity under standard enzyme assay conditions, at various $\mathrm{pH}$ levels ranging from 4.0 to 10.0. The following $0.1 \mathrm{M}$ buffer systems of varying $\mathrm{pH}$ were used: acetate buffer (NaAc-HAc) for $\mathrm{pH} 4.0$; phosphate buffer (NaH2PO4-Na2HPO4) for $\mathrm{pH} 7.0$; and $\mathrm{NaOH} /$ glycine buffer for $\mathrm{pHs} 8.0,9.0$ and 10.0. Stability was determined by measuring specific enzymatic activity under standard enzyme assay conditions after incubating the enzyme solution for $10 \mathrm{~min}$ at temperatures of $16,20,25,30$ and $37^{\circ} \mathrm{C}$. The results obtained showed that enzyme presented high stability at $\mathrm{pH} 8.0-9.0$, thermal stability being completely maintained up to $25^{\circ} \mathrm{C}$, after which activity gradually decreased (Figure 3C). In fact, many ADHs are generally unstable, low stability often hampering their industrial application (Hirakawa et al., 2004)

In summary, for the first time, a B. mori $\mathrm{ADH}$ gene was identified and the recombinant BmADH enzyme experimentally characterized. Soluble recombinant BmADH proteins from $E$. coli were produced to determine substrate specificity. In the oxidoreduction reaction, $\mathrm{BmADH}$ catalyzed the reduction of $\mathrm{NAD}^{+}$to $\mathrm{NADH}$ in the presence of ethanol, whereby the inference that ethanol was a substrate of $\mathrm{BmADH}$, and that the latter might be involved in ethanol metabolism in B. mori.

\section{Acknowledgments}

This work was supported by grants from the Jiangsu Sci-Tech Support Project-Agriculture (No. BE2008379), the National Program of High-tech Research and Development (863 High-Tech Program, No. 2008AA10Z145), and the National Natural Science Foundation (No. 30871826).

\section{References}

Adolph HW, Zwart P, Meijers R, Hubatsch I, Kiefer M, Lamzin V and Cedergren-Zeppezauer E (2000) Structural basis for substrate specificity differences of horse liver alcohol dehydrogenase isozymes. Biochemistry 39:12885-12897.

Atrian S, Sanchez-Pulido L, Gonzalez-Duarte R and Valencia A (1998) Shaping of Drosophila alcohol dehydrogenase through evolution: Relationship with enzyme functionality. J Mol Evol 47:211-221.

Benach J, Atrian S, Gonzalez-Duarte R and Ladenstein R (1999) The catalytic reaction and inhibition mechanism of Drosophila alcohol dehydrogenase: Observation of an enzyme- 
bound NAD-ketone adduct at 1.4 A resolution by X-ray crystallography. J Mol Biol 289:335-355.

Benach J, Winberg JO, Svendsen JS, Atrian S, Gonzalez-Duarte R and Ladenstein R (2005) Drosophila alcohol dehydrogenase: Acetate-enzyme interactions and novel insights into the effects of electrostatics on catalysis. J Mol Biol 345:579-598.

Branden C-I, Jornvall H, Eklund H and Furugren B (1975) The Enzymes. 3rd edition. Academic Press, New York, 103 pp.

Doga A (2010) Alcohol dehydrogenase and its simple inorganic models. Coord Chem Rev 254:916-937.

Gasperi G, Kafetzopoulos D, Christodoulidou A, Bouriotis V and Savakis C (1994) Isolation and partial characterization of two alcohol dehydrogenase isozymes from the medfly Ceratitis capitata. Insect Biochem Mol Biol 24:87-94.

Geer BW, McKechnie SW, Bentley MM, Oakeshott JG, Quinn EM and Langevin ML (1988) Induction of alcohol dehydrogenase by ethanol in Drosophila melanogaster. J Nutr 118:398-407.

Hirakawa H, Kamiya N, Kawarabayashi Y and Nagamune T (2004) Properties of an alcohol dehydrogenase from the hyperthermophilic Archaeon Aeropyrum pernix K1. J Biosci Bioeng 97:202-206.

Huo J, Shi H, Yao Q, Chen H, Wang L and Chen K (2010) Cloning and purification of recombinant silkworm dihydrolipoamide dehydrogenase expressed in Escherichia coli. Protein Expr Purif 72:95-100.
Mazi V, Cosmidis N, Loukas M, Clonis Y and Zouros E (1998) Biochemical differences between products of the ADH locus in olive fruit fly (Bactrocera oleae). Biochem Genet 36:259-269.

Oudman L, Van Delden W, Kamping A and Bijlsma R (1991) Polymorphism at the Adh and alpha Gpdh loci in Drosophila melanogaster: Effects of rearing temperature on developmental rate, body weight, and some biochemical parameters. Heredity 67:103-115.

Reid MF and Fewson CA (1994) Molecular characterization of microbial alcohol dehydrogenases. Crit Rev Microbiol 20:13-56.

Rella R, Raia CA, Pensa M, Pisani FM, Gambacorta A, De Rosa $\mathrm{M}$ and Rossi M (1987) A novel archaebacterial NAD+-dependent alcohol dehydrogenase. Purification and properties. Eur J Biochem 167:475-479.

Williamson VM and Paquin CE (1987) Homology of Saccharomyces cerevisiae ADH4 to an iron-activated alcohol dehydrogenase from Zymomonas mobilis. Mol Gen Genet 209:374-381.

Zhang ZH, Kang YM, Yu Y, Wei SG, Schmidt TJ, Johnson AK and Felder RB (2006) 11beta-hydroxysteroid dehydrogenase type 2 activity in hypothalamic paraventricular nucleus modulates sympathetic excitation. Hypertension 48:127133.

Associate Editor: Carlos F.M. Menck

License information: This is an open-access article distributed under the terms of the Creative Commons Attribution License, which permits unrestricted use, distribution, and reproduction in any medium, provided the original work is properly cited. 